\title{
ERRATA
}

Artigo orginalmente publicado com erro no nome do primeiro autor (saiu impresso Jonatan ao invés de Jonatas).

\section{Gorduras de descarte e componentes externos do corpo de novilhos e vacas de descarte de diferentes grupos genéticos}

Trim fat and external components of the body of steers and cull cows from different genetic groups

\author{
Jonatas Cattelam ${ }^{\mathrm{I}}$ Luís Fernando Glasenapp de Menezes ${ }^{\mathrm{II}}$ Julcemir João Ferreira' ${ }^{\mathrm{III}}$ João Restle \\ Dari Celestino Alves Filho' ${ }^{I}$ Ivan Luiz Brondani ${ }^{I}$
}

Para html ou PDF, acesse, respectivamente:

http://www.scielo.br/scielo.php?script=sci_arttext\&pid=S0103-84782010001200017\&lng=pt\&nrm=iso\&tlng=pt

ou

http://www.scielo.br/pdf/cr/v40n12/a811cr2822.pdf

IPrograma de Pós-graduação em Zootecnia (PPGZ), Universidade Federal de Santa Maria (UFSM), Santa Maria, RS, Brasil.

"Universidade Tecnológica Federal do Paraná (UTFPR), Campus Dois Vizinhos, Estrada para Boa Esperança, Km 04, 85660-000,

Dois Vizinhos, PR, Brasil. E-mail: luismenezes@utfpr.edu.br. Autor para correspondência.

IIIVale fertilizantes, Ponta Grossa, PR, Brasil. 